\title{
Discussion
}

\section{Cooking, Mechanical Processing, and the Discovery of Ignition Technology}

\section{Ronald Planer}

Australian National University, Acton, Australian Capital Territory 2601, Australia (ronald.planer@anu.edu.au). This paper was submitted $17 \mathrm{X} 17$ and accepted $20 \mathrm{X} 17$.

In his article "Control of Fire in the Paleolithic," Richard Wrangham (2017) advances a number of novel and insightful arguments in support of his cooking hypothesis. The main alternative hypothesis Wrangham considers is one we might call the "mechanical processing hypothesis." This hypothesis would seek to explain the suite of anatomical and behavioral innovations associated with erectines not in terms of cooking but rather in terms of nonthermal, mechanical processing of plant matter (as well as animal products). The main idea is that, like cooked food, ground or mashed-up raw food would have been easier to both chew and digest compared with unprocessed raw foods; hence, the adoption of mechanical processing might have led to relaxed selection pressure for maintaining a large and powerful craniofacial anatomy.

While the two hypotheses are construed as competitors by Wrangham, they might work together. Many-perhaps mostof the adaptations of modern humans to eating cooked food likely required near-constant access to cooked food to evolve; hence, ignition technology was also presumably required. How strong of a constraint is this? As John Gowlett (2016) recently pointed out, "Ignition is often assumed to have required a cognitive advance. Yet the simplest kindling technique of rubbing a stick in a groove in a wooden 'hearth' requires no more than power and basic skill” (5). I agree with Gowlett that primitive ignition technology is behaviorally simple. But it does not follow that a wood-on-wood method for producing fire would have been easy for erectines to discover.

Mechanical processing of dry plant matter could be relevant here. Both chimpanzees and bonobos use wooden implements to extract food from various sources, so it is likely that our last common ancestor also did (Roffman et al. 2015). Thus, the use of wooden implements to process food poses no deep mystery. Moreover, it is plausible that wooden platforms were sometimes used in the place of stone ones: the interior of a piece of tree bark, for example, would make for a flat, elongated surface while also serving as a natural container (given its curved sides) that might be efficiently transported.

Such a suggestion fits nicely with one of Wrangham's arguments for the cooking hypothesis, namely, that hunting effort presupposes the availability of easily chewed and digested foods to be consumed on days when hunting is unsuccessful. If erectines regularly hunted - and it seems clear that they didthen it is plausible that other individuals processed food in advance for the hunters to consume on their return. This may have served to further incentivize the use of wooden containers of some sort, but more importantly it means that processing activities would have been carried out for extended periods of time by certain nonhunting individuals (relative to the amount of time needed to process food just for oneself). Moreover, given the repeated performance of these activities, one would expect that they became routinized, giving rise to faster-paced performance. Such conditions would have been quite conducive to observing the causal connection between heat (which these hominins would have already associated with fire) and wood-on-wood friction. From here it is not too large a step to imagine the intentional manufacture of heat in this way, producing smoke and eventually an ember.

In sum, the practice of regular, mechanical processing of food using wooden implements and platforms may well have paved the way for the discovery of primitive ignition technology. On this view, such a discovery would not owe to a "cognitive advance" but would simply be a natural outgrowth of activities already central to erectine lifeways. Thus, the cooking hypothesis and the mechanical processing hypothesis might be seen as two pieces of a larger story about how humans came to control fire and then depend on it: many of the anatomical and behavioral innovations of erectines may well have resulted from the regular consumption of cooked food, but the evolution of the ability to cook food may itself have depended on an earlier erectine regime of mechanical processing of plant foods, indirectly leading to the discovery of ignition technology.

\section{References Cited}

Gowlett, John A. J. 2016. The discovery of fire by humans: a long and convoluted process. Philosophical Transactions of the Roval Society B 371(1696): 20150164.

Roffman, Itai, Sue Savage-Rumbaugh, Elizabeth Rubert-Pugh, André Stadler, Avraham Ronen, and Eviatar Nevo. 2015. Preparation and use of varied natural tools for extractive foraging by bonobos (Pan paniscus). American Journal of Physical Anthropology 158(1):78-91.

Wrangham, Richard. 2017. Control of fire in the Paleolithic: evaluating the cooking hypothesis. Current Anthropology 58(suppl.):S303-S313. 